\title{
(Re)visitando o Estado Novo no Brasil: uma análise da censura e a difusão cultural dos livros nas bibliotecas
}

\author{
Alessandra Nunes de Oliveira \\ Mestranda; Universidade Federal do Pará, Belém, PA, Brasil; \\ alessandranunesoliveira@gmail.com \\ Luiz Eduardo Ferreira da Silva \\ Doutor; Universidade Federal da Paraíba, João Pessoa, PB, Brasil; \\ luizeduardo.ufpb@gmail.com \\ Jetur Lima de Castro \\ Mestrando; Universidade Federal do Pará, Belém, PA, Brasil \\ jetur.er@gmail.com
}

\begin{abstract}
Resumo: O artigo traz uma discussão sobre as relações da censura com as medidas de implementação da difusão cultural dos livros nas bibliotecas no Estado Novo no Brasil. Configura-se como uma abordagem teórica de cunho histórico, bibliográfico e documental, em que foi adotado o conhecimento indiciário sobre as quais evidenciam-se os aspectos interpretativos de outras formas do saber que partilham das pistas e das pegadas por meio do conhecimento indireto. São feitas considerações sobre o desenvolvimento do Instituto Nacional do Livro nas bibliotecas, sob a influência do Estado Novista, e sobre a relação da censura com o Departamento de Imprensa e Propaganda, com o qual estava coligada aos interesses do governo em questão em relação à expansão e à difusão dos livros. Considera-se que o livro e a leitura foram um esforço grande na política de Vargas com o Estado Novo, com a criação do Instituto Nacional do Livro, um ato perigoso, diga-se, na propaganda, instanciado em nome da moral e dos bons costumes e, por conseguinte, alvo da censura e da repressão à liberdade de expressão de grandes autores brasileiros citados no estudo, como Jorge Amado, Monteiro Lobato, Cecília Meireles e José Lins do Rego. Portanto, é necessário questionar, visto que ainda há uma tendência aos vestígios conservadores, como o do Estado Novo, devido às tradições habituais instauradas nos ambientes de trabalho, ao clima de vigilância nas instituições e às políticas comuns em bibliotecas.
\end{abstract}

Palavras-chave: Estado Novo - Brasil. Instituto Nacional do Livro. Censura. Livros. Bibliotecas. 


\section{Introdução}

Considerando as apreensões e as singularidades que propiciam olhares rumo às trajetórias sociais, culturais e políticas da sociedade, nas diferentes épocas, e nas interpretações da história no século XX e seus processos hegemônicos (HOBSBAWM, 1998), neste texto, apresenta-se uma discussão sobre as relações da censura com as medidas implementadas na difusão cultural dos livros nas bibliotecas, no Estado Novo, no Brasil.

Este estudo configura-se como uma abordagem teórica de cunho histórico, bibliográfico e documental que, sob o ponto de vista de Tachizawa e Mendes (2006), visa proporcionar um espaço de compreensão e de debate sobre as questões que intrigam a realidade. Tenta explicar um problema, usando o conhecimento disponível das teorias publicadas em livros ou obras homólogas, documentos impressos e digitais, vídeos e documentos oficiais indispensáveis aos estudos históricos (GIL, 2002).

Para o desenvolvimento da pesquisa, foram adotados o conhecimento indiciário e outras formas do saber que se partilham nas pistas apresentadas por Ginzburg (1989). A descrição indiciária remonta aos tempos primigênios, quando o homem era um caçador ${ }^{1}$ que reconstruía os caminhos nas pegadas deixadas como vestígios, para construir fatos. Nessa abordagem, o “[...] pesquisador indiciário se torna um 'detetive metodológico', que, através das várias maneiras de investigar, acaba adotando o aspecto 'intrínseco da subjetividade' e da alteridade ontológica e dialógica [...]" (SILVA, 2013, p. 26).

A partir das evidências, indagou-se: como o Instituto Nacional do Livro (INL) contribuiu, junto com o Departamento de Imprensa e Propaganda (DIP), para difundir a cultura dos livros no Brasil? E como o DIP trabalhava com a restrição e a censura a livros de autores brasileiros que iam de encontro ao governo de Vargas no Estado Novo?

Tendo em vista as questões apresentadas, analisou-se o desenvolvimento do INL nas bibliotecas, sob a influência do Estado Novo, e a relação da censura com o DIP, com o qual estava coligada aos interesses do governo em questão na expansão e na difusão dos livros no Brasil. 
No fim, considera-se que o livro e a leitura foram um esforço grande na política de Vargas com o Estado Novo, com a criação do INL, um ato perigoso, diga-se, na propaganda, instanciado em nome da moral e dos bons costumes e, por conseguinte, alvo da censura e da repressão à liberdade de expressão de grandes autores brasileiros citados no estudo, como Jorge Amado, Monteiro Lobato, Cecília Meireles e José Lins do Rego.

Convém enfatizar que é necessário questionar sempre, uma vez há uma tendência aos vestígios conservadores, como o do Estado Novo, devido às tradições habituais instauradas nos ambientes de trabalho, ao clima de vigilância nas instituições e às políticas comuns em bibliotecas.

\section{O Estado Novo no Brasil}

Getúlio Vargas, grande mentor do Estado Novo no Brasil, nasceu em São Borja (RS), no dia 19 de abril de 1882. Era filho de Manuel do Nascimento Vargas e de Cândida Dornelles Vargas. Formou-se em Direito pela Universidade de Porto Alegre, entrou na política ainda jovem (GETÚLIO..., 2010) e foi deputado estadual (1909-1913 e 1917-1922), deputado federal (1923-1926) e senador (1946-1947). Na Câmara dos Deputados, passou de político regional a personagem nacionalmente articulado, que assumiu o cargo de ministro de Estado da Fazenda em 1927 e, em 1930, liderou o processo revolucionário que derrubou a chamada República Velha e marcou a história brasileira (D’ARAUJO, 2011).

Tomou o poder em 1930, depois de liderar a Revolução de 1930, e seu governo foi marcado pelo populismo e pelo nacionalismo. Em 1937, o Congresso Nacional foi fechado e instalou-se o Estado Novo. Getúlio Vargas trouxe para a modernidade seu espírito governamental em um Brasil que, até então, pouco ou quase nada havia progredido no quesito infraestrutura e desenvolvimento econômico e nos direitos para a classe trabalhista, que ainda consistia em grande parte de trabalhadores rurais. Em comparação com essa situação, Getúlio Vargas trouxe um plano de Governo, chamado de Estado 
Novo, datado de 1937 a 1945, que se apresentou como uma política ligada ao progresso e aos investimentos nacionais.

Com a implantação do Estado Novo, Vargas cercou-se de poderes excepcionais. O Brasil, até então, basicamente agrário e exportador, foi-se transformando numa nação urbana e industrial. Promotor da industrialização e interventor nas diversas esferas da vida social, o Estado voltou-se para a consolidação de uma indústria de base e passou a ser o agente fundamental da modernização econômica. (PANDOLFI, 1999, p. 10).

Agregada à modernização e à valorização interna com o plano de crescer, a modernidade de Getúlio Vargas tinha limites, pois, ao mesmo tempo em que ocorria o crescimento nacional, seu governo se colocava ao lado da política nacionalista e centralizadora. Tal situação lembra a expressão de "modernidade conservadora" de Moore Júnior (1975), o que remete ao fato de o governo de Getúlio Vargas, mesmo se prontificando para empreender internamente, estabeleceu-se com as mesmas características das antigas políticas obsoletas em relação a proceder com vertente centralizadora.

O ponto de partida para a ditadura de Getúlio construiu-se por meio da Constituição de 1937 que estabelecia leis que limitavam tanto os políticos quanto a população brasileira e cujo conteúdo mencionava a questão centralizadora e opressora para instituir seu governo como autoridade suprema e dar início à ditadura varguista.

Jambeiro et al (2004, p. 89) esclarecem que a Constituição Federal de 1937 acabava com o "sistema republicano federativo, extinguia os partidos políticos [...], restringia a manifestação do pensamento, intensificava a repressão aos crimes contra a segurança nacional e previa a nomeação de interventores para as unidades federativas". Nesse contexto, restringir e reprimir tornaram-se práticas de sua ditadura. Vale enfatizar que o governo getulista recebeu grande influência das tiranias que estavam se alastrando pela Europa nesse período, como o Nazismo e o Fascismo que, objetivados pelo nacionalismo, criaram suas ditaduras. 
Capelato (1999, p. 167) ressalta que "[...] é preciso levar em conta a importância da inspiração das experiências alemã e italiana nesse regime, especialmente no que se refere à propaganda política". Se a Alemanha tinha um ditador que manifestava o nacionalismo e usava a propaganda para incutir o populismo e a ideologia e, consequentemente, instaurar a ditadura, o Brasil também detinha a tríade nacionalismo, propaganda e ditadura.

Então, se, de um lado, o nacionalismo de Vargas deu a iniciativa para a modernidade no país e a valorização interna; de outro, por meio da Constituição de 1937, a referente lei prescrevia a "liberdade", mas, até certo ponto, no limite que não ultrapassasse os interesses do governo de Vargas, visto que ultrapassar a barreira da liberdade de expressão poderia acarretar a censura. O Art. 122, parágrafo 15, refere que, “[...] com o fim de garantir a paz, a ordem e a segurança pública, a censura prévia da imprensa, do teatro, do cinematográfico, da radiodifusão, facultando a autoridade competente proibir a circulação, a difusão ou a representação [...]" (BRASIL, 1937, p. 31).

Em meio às interdições e às imposições da Constituição de 1937, o governo de Getúlio Vargas tomou medidas para impulsionar seu populismo e sua ideologia, no que diz respeito a utilizar o campo da educação como forma de disciplinar ideologicamente a sociedade. Assim, refere Bomeny (1999, p. 139), "a educação talvez seja uma das traduções mais fiéis daquilo que o Estado Novo pretendeu no Brasil. Formar um 'homem novo' para um Estado Novo, conformar mentalidades". Com esse novo enfoque estadonovista, a intenção era impulsionar a produção livresca do país, com a criação de um instituto que atenderia às ideologias nacionalistas de Vargas e que marcaria o Brasil com sua produção livresca nacionalista, chamado de Instituto Nacional do Livro (INL).

\section{Instituto Nacional do Livro (INL)}

Havia chegado a hora de o próprio governo liderar as publicações e, ao mesmo tempo, disseminar os ideais de cultura nacional. A partir desse plano de interesse, o ministro da Educação e da Saúde, Gustavo Capanema, aderiu à iniciativa de criar o $\mathrm{INL}^{2}$, como forma de "zelar" pela educação brasileira. 
Gustavo Capanema ${ }^{3}$ tomou a iniciativa de emitir uma carta para o presidente Getúlio Vargas, falando a respeito da importância de se criar um Instituto do Livro.

A seguir, apresenta-se um parágrafo da carta emitida que chama à atenção para a comparação entre os prós e os contras de Gustavo Capanema a respeito do livro:

O livro não é só o companheiro, amigo, que instrui que diverte que consola. É ainda é, sobretudo, o grande semeador que, pelos séculos afora, vem transformando a face da Terra. É, portanto dever do Estado proteger o livro, não só promovendo e facilitando a sua produção e divulgação, mas ainda vigiando no sentido de que ele seja não o instrumento do mal, mas sempre inspirador dos grandes sentimentos e das nobres causas humanas. (CAPANEMA, 1937, p. 25586).

Capanema atribuía uma grande importância aos livros, porém com limites, já que seu controle era voltado para as obras que satisfaziam aos interesses do estado, pois entendia que, a depender do livro, ele poderia ser utilizado para o "mal" de uma sociedade.

Assim, considerando o posicionamento do ministro, partimos para a análise dos indícios de repreensão e censura, pois, de forma implícita, Capanema estava sugerindo que o Estado tinha o dever de "vigiar" o que a sociedade deveria ler. Em meio ao contexto, Gustavo Capanema dava motivos para se criar o INL, a fim de ter uma instituição que promoveria livros como os de interesses mencionados na carta. Assim, impulsionado pelo populismo da modernização, Getúlio Vargas atendeu ao pedido do Ministro Gustavo Capanema e criou o INL que entrou em vigor em 1937, e nomeou Augusto Meyer ${ }^{4}$ para assumir sua direção.

O INL localizou-se no quarto andar da Biblioteca Nacional Brasileira. Com sua criação, era preciso estabelecer seus objetivos. Por essa razão, entrou em vigor o Decreto-Lei $n^{\circ}$ 93, de 21 de dezembro de 1937, que responsabilizou o INL pelas publicações e pela circulação de livros e pela criação de bibliotecas no território brasileiro. 


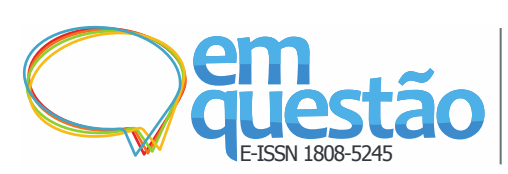

$\mathrm{O}$ art. 2 do decreto determinava que os objetivos do INL eram de:

a) Organizar e publicar a Enciclopédia Brasileira e o dicionário da Língua Nacional, revendo-lhes as sucessivas edições;

b) Editar toda sorte de obras raras ou preciosas, que sejam de grande interesse para a cultura nacional;

c) Promover as medidas necessárias para aumentar, melhorar e baratear a edição de livros no país bem como para facilitar a importação de livros estrangeiros

d) Incentivar a organização e auxiliar a manutenção de bibliotecas públicas em todo o território nacional (BRASIL, 1937, p. 25586).

Alguns dos objetivos que o INL se prestou a atingir não puderam ser concretizados, como, por exemplo, fazer a enciclopédia brasileira, influenciada pelo exemplo da Enciclopédia Italiana Treccani, concluída no governo de Mussolini. Mais uma vez, o INL não conseguiu traçar os objetivos que vinham sendo almejados desde o extinto Instituto Cairu, pois, como a enciclopédia brasileira foi planejada com poucos recursos, não foi possível concretizá-la (HALLEWELL, 2005).

No que se refere ao objetivo do INL para com as obras raras, o instituto se encarregou de fazer obras importantes e exclusivas, que retratavam as raízes históricas luso-brasileiras, em edições, a fim de que fossem disseminadas para o público, por meio da Biblioteca Nacional do Brasil. Os autos de devassa da inconfidência mineira, A demanda do Santo Graal, As cartas chilenas e Corografia brasílica (SCHWARTZMAN, 1982) foram alguns dos livros que o INL tratou de levar para perto do público, viabilizando a cultura nacional.

O terceiro objetivo, presente no decreto do INL, era de demandar a circulação de livros em todo o território brasileiro e de levar a cultura nacional para o exterior, por meio das obras raras editadas pelo INL, que passou a produzir muitos livros. Oliveira (1994, p. 46) chama de livros "culturalmente adequados" aqueles que se subordinassem, cultural e educacionalmente, à ideologia estatal em que deveriam circular.

Considerando o exposto, a pesquisa situou algumas obras produzidas pelo INL que estavam disponíveis no site do Centro de Pesquisa e Documentação Histórica (CPDOC), para averiguar como ocorria o processo 
ideológico por meio dos livros. As obras intelectuais se subsidiavam na mesma esfera político-ideológica do Estado Novo, que consistia em propagar a literatura produzida nesse regime para combater a pobreza, o progresso do homem e a exaltação do valor ao trabalho, ao progresso e ao nacionalismo. Esses objetivos “[...] se unificavam em uma mesma e grande meta: transformar o homem em cidadão/trabalhador, responsável por sua riqueza individual e também pela riqueza do conjunto da nação.” (GOMES, 1982, p. 152).

Entre as obras publicadas, estavam as obras históricas e, principalmente, as de teor didático, algumas em forma de cartilhas infanto-juvenis, cujo conteúdo abordava, explicitamente, o despertar do nacionalismo ou a figura de Vargas.

Seguem algumas das obras situadas:

Figura 1 - Capa do livro para a juventude

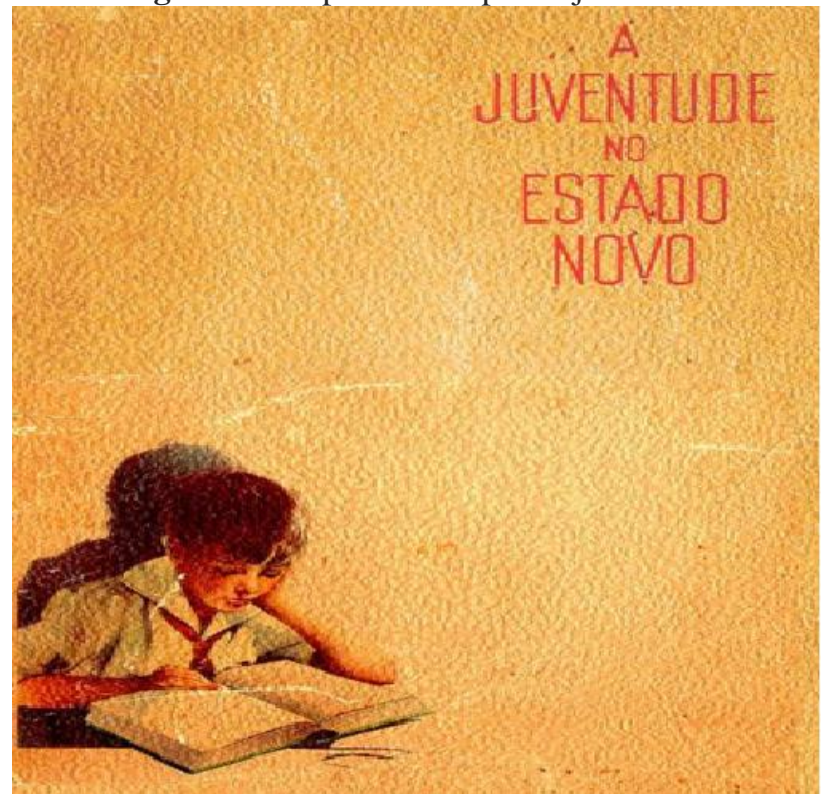

Fonte: Fundação Getúlio Vargas ([19--]). 

Lima de Castro

Figura 2 - Cartilha de 1942

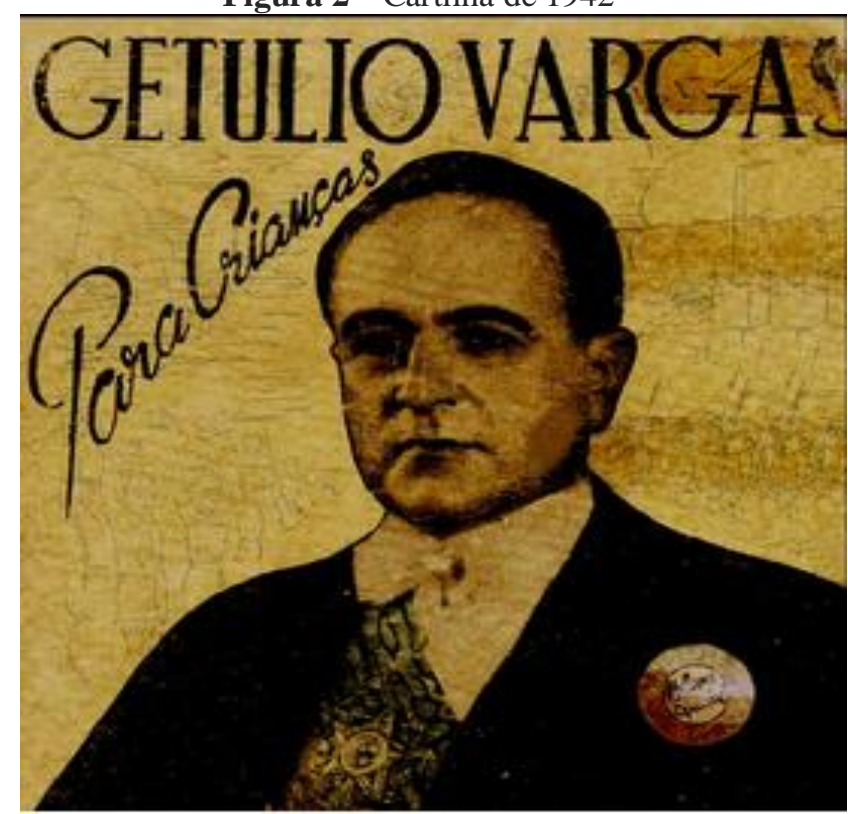

Fonte: Fundação Getúlio Vargas (1942).

Os livros A juventude no Estado Novo (Figura 1) e Getúlio Vargas para crianças (Figura 2) são exemplos de como o INL se portava perante a figura de Vargas e o ideal nacionalista para a educação infanto-juvenil, com conteúdo tipicamente didático e ilustrações relativas à figura paternal de Vargas com as crianças.

Figura 3 - Biografia sobre a figura de Vargas

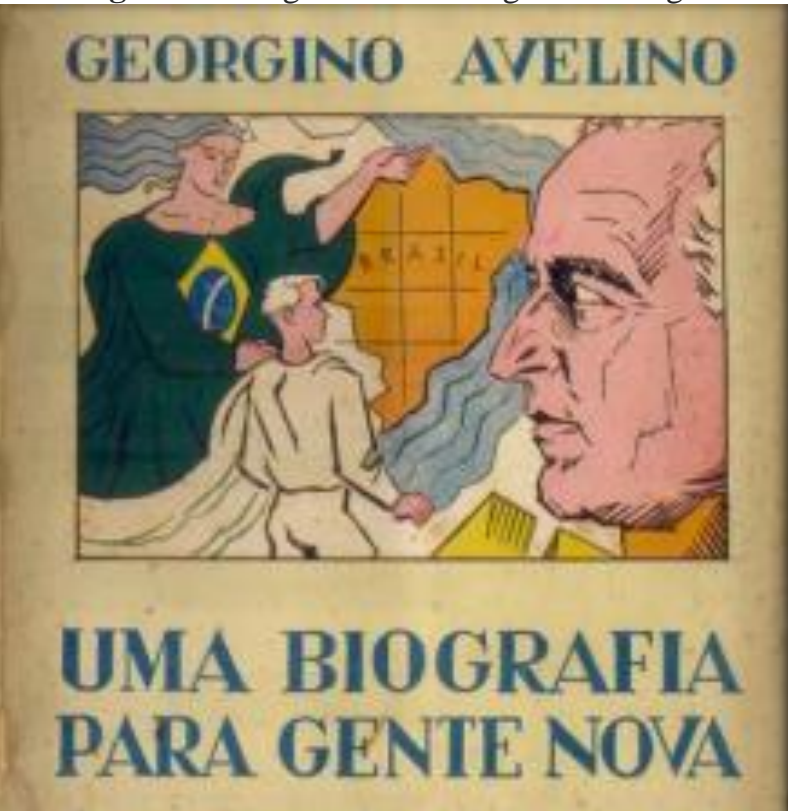

Fonte: Adaptado de Leilões BR (c2017). 
Figura 4 - Sobre o Marechal Floriano Peixoto

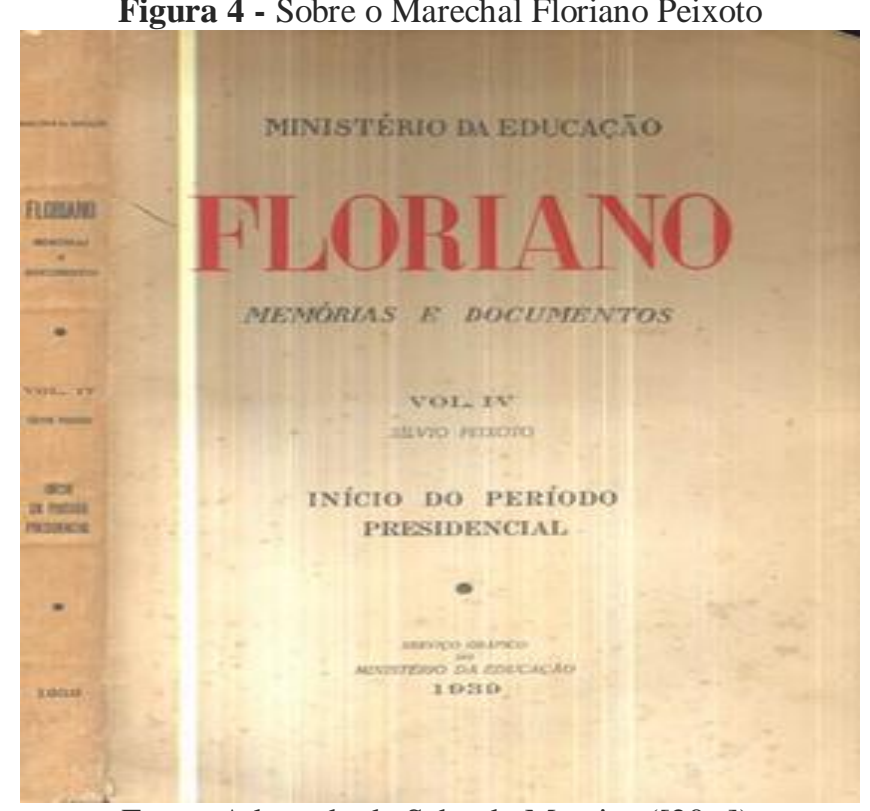

Fonte: Adaptado de Sebo do Messias ([20--]).

A obra Uma biografia para gente nova (Figura 3) retrata a personalidade de Getúlio Vargas e Memórias e documentos (Figura 4), de Floriano Peixoto, representa o centenário de nascimento do Marechal Floriano Peixoto (LEITÃO, 2011).

O fato era que o INL objetivava produzir livros que chegassem a todos os campos intelectuais, desde os simples estudantes até os mais ativos leitores. Era o Plano Geral de Divulgação, idealizado pelo ministro Gustavo Capanema, que entrava em vigor, que dizia: "O plano deve ser traçado e orientado pelo Instituto, procurando atingir desde Academias de Letras, Secretarias de Estado, Prefeituras Municipais, até bibliotecas, colégios, universidades e associações" (LEITÃO, 2011, p. 109).

No entanto, com a grande proporção de exemplares que o INL estava promovendo e produzindo, era preciso haver demandas, logo, entrava em vigor mais um dos objetivos do referido Instituto - o de criar bibliotecas em todo o território brasileiro e de investir nelas.

Sob o ponto de vista de Oliveira (1994), esse era um dos planos principais de Augusto Meyer, que elaborou dois projetos inovadores para bibliotecas: o primeiro consistia em criar 25 bibliotecas populares no Rio de Janeiro, que receberia doações do INL; e o segundo consistia em criar 
bibliotecas populares regionais nas cidades de Recife, Salvador, Belém, Belo Horizonte, São Paulo, Rio de Janeiro e Porto Alegre.

Como consequência, as bibliotecas cresceram significativamente nos primeiros anos de existência do instituto. De acordo com Soares,

“[...] até dezembro de 1943, mais de 2.000 bibliotecas, em todo o País, estavam inscritas, recebendo doações. A atuação do INL, apesar de sua curta existência, era apontada por vezes, como responsável pela viabilização de muitas bibliotecas públicas". (SOARES, 2007, p. 71).

É importante ressaltar que o INL era sobremaneira "influente" para a cultura livresca e educacional do país, devido aos investimentos em bibliotecas e em obras exclusivas a que a sociedade tivesse acesso.

Graças a essa instituição as bibliotecas perdidas no interior, longe dos grandes centros intelectuais, recebem metodicamente lotes de livros. Se não tivessem esse auxilio, o que seria dessas bibliotecas esquecidas das autoridades locais, sempre preocupadas com problemas que julgam mais urgentes? (MORAES, 1943, p. 38-39).

Ao analisar as propostas do INL, em primeiro plano, considera-se ser um órgão que contribui para propagar a cultura, a leitura e a atribuição de valor às bibliotecas. Todavia, devido aos avanços nos investimentos das bibliotecas, partiu-se para a seguinte reflexão: até que ponto se pode considerar que as publicações e as iniciativas criadas pelo INL eram benéficas para a sociedade do período do Estado Novo?

Sobre essa questão, Oliveira (1994, p. 46) compreende que, "no quadro ideológico do Estado Novo, as medidas implementadas na área de biblioteca pública centravam-se no uso das bibliotecas para a preservação e a divulgação da cultura oficial e para a formação de cidadãos talhados conforme a cultura", uma vez que a cultura central do país, nesse período, estava atrelada à ideia de civismo de fazer de seus cidadãos "homens de bem". Contudo, essa questão estava dominada pela ideologia do pensamento excludente sobre o que deveria ser lido ou pensado. 
D’Araújo refere que “[...] várias histórias de 'Vargas para crianças' chegaram às bibliotecas, demonstrando como, desde o nascimento das crianças, Getúlio estaria fadado a liderar seu povo em um grande projeto.” (D’ARAÚJO, 2000, p. 36). Isto é, os acervos das bibliotecas estavam repletos de livros, mas sua disseminação circulava com os pensamentos ideológicos propiciamente nacionalistas, com a finalidade de educar. Conforme Leitão, “[...] O INL priorizou a propagação do livro como contribuição ao fortalecimento dos ideais do governo de Getúlio Vargas, da mesma forma que nos regimes ditatoriais, como os de Salazar e Mussolini.” (LEITÃO, 2011, p. 110).

Isso contraria os objetivos que a leitura realmente deve proporcionar que o "[...] leitor trabalhe, interiormente, a sua inocência e espírito crítico, em vez de promover o achismo.” (FRANKE JUNIOR, 2013, p. 84). Em consideração ao atual contexto político brasileiro, é estimulante considerar que as bibliotecas devem proporcionar à sociedade "[...] condições básicas para uma aprendizagem contínua, para uma tomada de decisão independente [...] o conhecimento e a informação de todos os gêneros." (FEDERAÇÃO INTERNACIONAL..., 1994, doc. não paginado), o que não era visto nas intenções do INL, porque, nas bibliotecas, não havia uma diversidade de conhecimentos sobre a leitura com espírito crítico.

\section{Departamento de Imprensa e Propaganda (DIP)}

O INL encarregou-se de ser o difusor de leitura, embora, em 1940, entrasse em vigor o Departamento de Imprensa e Propaganda (DIP), que fiscalizaria as obras culturais e intelectuais nacionais. Essa autoridade incumbia-se de fiscalizar os meios citados na Constituição de 1937, com o objetivo de reverenciar e de proteger a imagem de Vargas, para fazer seu populismo e fiscalizar os diversos meios de informação em nome da honra e da moral brasileiras. Esse órgão se tornou a marca do seu regime. 
como função elucidar a opinião pública sobre as diretrizes doutrinárias do regime, atuando em defesa da cultura, da unidade espiritual e da civilização brasileira. (CAPELATO, 1999, p. 172).

Assim, o DIP passaria a exercer total influência em todos os meios de comunicação e informação, como as estações de rádio, a imprensa, a música, o cinema, o teatro e, até mesmo, as expressões intelectuais, como livros e bibliotecas. Na análise de Leitão, “[...] o governo de Getúlio Vargas contribuiu para que a cultura de censura no país se tornasse fortalecida e praticada por diferentes instâncias oficiais, aumentando os obstáculos para a impressão e circulação de livros.” (LEITÃO, 2011, p. 102).

Como havia vários meios para fiscalizar, o departamento precisou ser dividido em especialidades (Figura - 5) para que nenhum fosse negligenciado e, ao mesmo tempo, utilizado em benefício do governo.

Figura 5 - Regimento do Departamento de Impresa e Propaganda (DIP) de 1939

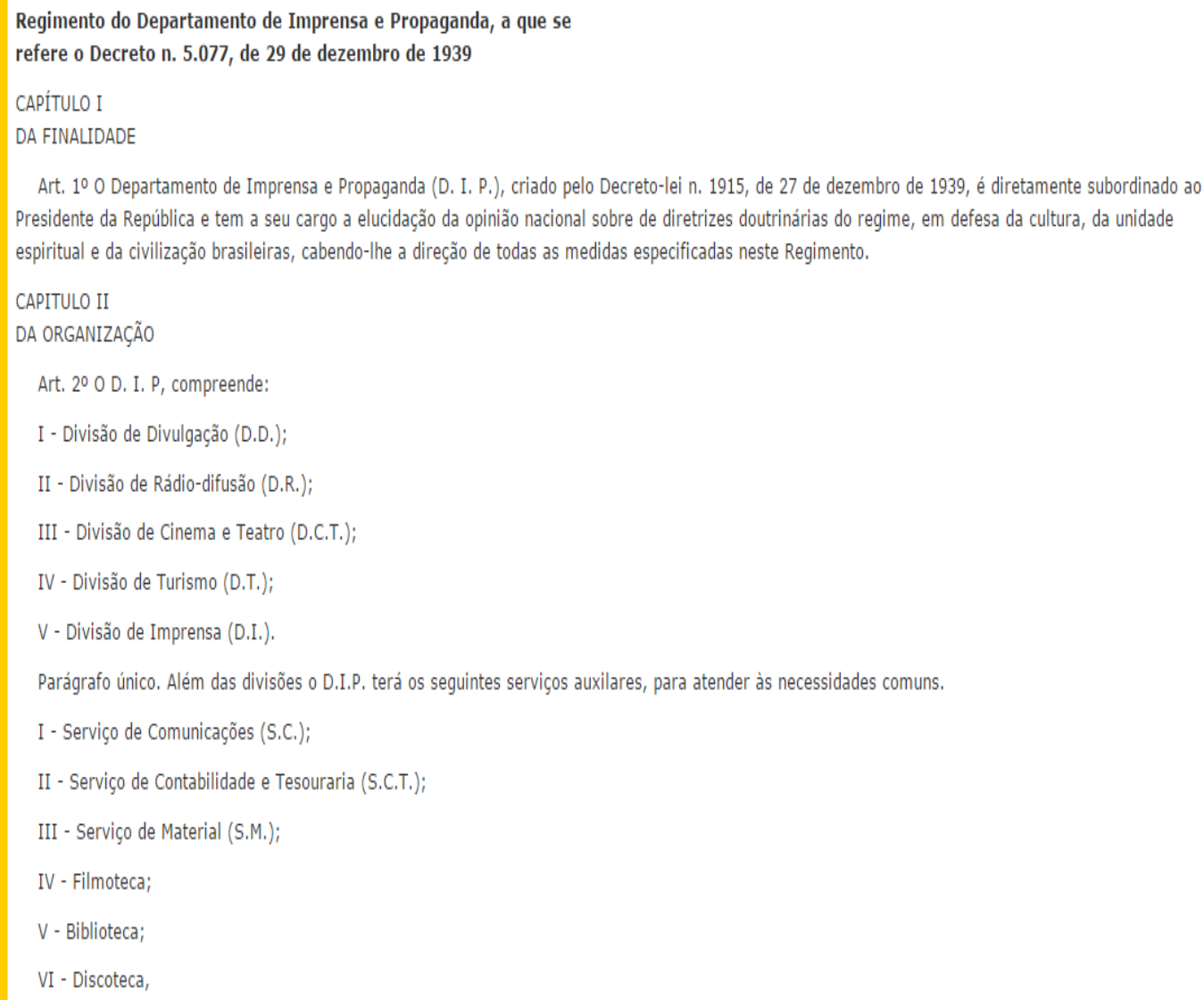

Fonte: Adaptado de Brasil (1939). 
A ordem das divisões era: “[...] divisão de divulgação, divisão de radiodifusão, divisão de cinema e teatro e divisão de imprensa [...]" (JAMBEIRO et al., 2004, p. 115). Todas as divisões foram incumbidas de disseminar a imagem e a ideologia de Vargas. Em contrapartida, utilizou-se a censura nas expressões, que, de alguma forma, atingiria a paz, a ordem ou a segurança.

No que se refere à divisão de radiodifusão, o objetivo era levar os interesses políticos em sua programação, para “[...] vulgarizar as realizações do governo e esclarecer a opinião pública sobre os problemas do momento [...]" (JAMBEIRO et al., 2004, p. 112). Com esse intuito, foi criada a Hora do Brasil, hoje chamada de A voz do Brasil. Contudo, na antiga programação, eram emitidos os feitos do Governo Vargas, e os problemas citados na programação eram cuidadosamente averiguados, para que não se reportassem para a liderança de Vargas.

A divisão de radiodifusão consistia em averiguar as letras musicais que tocariam nas rádios e passavam pela avaliação do DIP, como no caso da música de Ataulfo Alves, $O$ bonde São Januário, cuja versão original enaltecia "a boa vida" de quem não trabalhava, no trecho, "o bonde de São Januário leva mais um sócio otário, só eu não vou trabalhar". Em um governo que tinha a ideologia trabalhista, a letra certamente foi censurada pelo DIP e mudou para "o bonde São Januário leva mais um operário, sou eu que vou trabalhar", com o fim de engrandecer o trabalho. Os compositores foram incentivados a abordar temas em prol do trabalho e da valorização nacional, caso contrário, suas músicas não teriam visibilidade devido ao processo de censura do DIP.

A música de Ary Barroso, Aquarela do Brasil, retrata fielmente as letras almejadas pelo governo de Getúlio Vargas, com a exaltação nacional "Brasil, terra boa e gostosa", e o ritmo popular, o samba, que ocasionou a expressão cultural que o Estado Novo se propunha a divulgar de um Brasil longe de problemas sociais. Conforme Novaes (2011, p. 42), tais problemas "eram jogados para baixo do tapete", pelo viés implícito de letras com valorização 
nacional que se estimavam fazer e que, na realidade, não correspondiam aos fatos sociais.

No contexto da divisão de cinema e teatro, os roteiros destacavam o nacionalismo, como o filme $O$ descobrimento do Brasil, que enaltecia a raiz do povo brasileiro e as riquezas de sua terra, assim como os cines jornais que eram apresentados nas salas de cinema antes dos filmes, com exibição obrigatória, e "mostravam as comemorações e as festividades do governo e os atos das autoridades, que tinham a missão de exaltar a figura de Vargas e seus feitos de governo" (GARCIA, 2005, p. 149).

O grupo de Divisão de Divulgação (DD) tinha a função de fiscalizar a liberdade intelectual, isto é, obras e autores de publicações impressas, especialmente os livros. No art. $6^{\circ}$, do Decreto ${ }^{\circ}$ 5.077, de 29 de dezembro de 1939, a DD ressaltava, em algumas das alíneas, que era preciso fiscalizar os livros, para que as obras atingissem o dever nacionalista e, em contrapartida, usar a censura para os conteúdos conceituados como impróprios para a nação. Assim, à Divisão de Divulgação competia:

a) a elucidação da opinião nacional sobre as diretrizes doutrinárias do regime, em defesa da cultura, da unidade espiritual e da civilização brasileiras; b) interditar livros e publicações que atentem contra o crédito do País e suas instituições, e contra a moral; c) combater por todos os meios a penetração ou disseminação a qualquer ideia perturbadora ou dissolvente da unidade nacional (BRASIL, 1939, p. 29444, grifo nosso).

Nessas alíneas, podem-se analisar justificativas muito utilizadas por aqueles que recorrem à censura. Expressões como "em defesa da civilização", “contra a moral" e "ideia perturbadora" são constantemente pronunciadas em gestões ditatoriais, que, em um primeiro momento, denotam que só visam à organização, à civilização ou a um bem para todos. Vale ressaltar que, dificilmente, a censura manifesta-se de forma alarmante. Na maioria das vezes, ela surge sutilmente, de forma velada, em palavras de bom grado e é considerada, até mesmo, inofensiva por aqueles que a praticam, mas que, se 
estudada e interpretada detalhadamente, consegue-se entender que, em seu propósito, a censura é configurada.

Pode-se afirmar que seu significado remete aos objetivos expostos no Decreto da Divisão de Divulgação. Ainda em relação à censura, Vergueiro assevera que "[...] é um esforço por parte de um governo, organização, grupo ou indivíduo evitar que as pessoas leiam, vejam ou ouçam o que pode ser considerado como perigoso ao governo ou prejudicial à moralidade pública." (VERGUEIRO, 1978, p. 22). Logo, no que diz respeito ao que pode ser "prejudicial", o órgão do DIP comprometeu-se a usar esse objetivo para proibir a produção e a circulação de livros.

Devido a esse novo contexto, os autores não tinham mais autonomia para lançar suas obras. O Estado Novo tomou medidas drásticas em relação às obras, cujas páginas faziam referência à oposição varguista, como autores de cunho comunista. Os considerados exóticos, ou que, mesmo sutilmente, contrariassem o Estado, teriam suas criações impedidas. No que diz respeito aos que já haviam escrito sobres esses assuntos, suas obras seriam retiradas de circulação.

Quanto aos livros que estavam em circulação, o DIP tomou medidas rápidas a favor da "purificação" nacional literária. Os livros considerados nocivos para a sociedade foram procurados em todos os cantos do Brasil para sair de circulação (VIANNA; SILVA; GONÇALVES, 2014, p. 14). Obras de autores como Monteiro Lobato, Jorge Amado e José Lins do Rego estavam entre as mais perseguidas, assim como as obras traduzidas e adaptadas não escaparam da fúria do DIP.

\section{Censura registrada: o livro como ato "perigoso"}

Os livros considerados nocivos para a sociedade foram procurados em todos os cantos do Brasil para saírem de circulação (VIANNA; SILVA; GONÇALVES, 2014)

Na Divisão de Divulgação (DD), estava inserido o dever de fiscalizar a liberdade intelectual, isto é, obras e autores de publicações impressas, 
especialmente os livros. No art. $6^{\circ}$, do Decreto de $\mathrm{n}^{\circ}$ 5.077, de 29 de dezembro de 1939, a DD ressaltava, em algumas das alíneas, a obrigação de fiscalizar os livros para que atingissem o dever nacionalista e, em contrapartida, usar da censura para os conteúdos conceituados impróprios para a nação.

Distintas obras foram tão perseguidas que algumas editoras começaram a sofrer danos, faliram e fecharam as portas. De acordo com Hallewell, “[...] a perda financeira ocasionada por essa destruição em massa de quaisquer livros a que alguém em posição fizesse objeção foi suficiente para desativar algumas editoras menores." (HALLEWELL, 2005, p. 45). Para evitar prejuízos, não só as editoras passaram a limitar seus investimentos nas obras, porque temiam que as publicações fossem censuradas, mas também os autores que, para não perder seus espaços no meio editorial, passaram a analisar os próprios escritos e a restringir seus pensamentos para que suas obras não fossem impedidas de ser produzidas.

Esse procedimento das editoras e dos autores era uma forma de se autocensurar. Trata-se de casos em que o sujeito censura a si mesmo, por medo de ser recriminado por terceiros. Isso é o que Bahia chama de "[...] censura interna. É a censura que o próprio veículo pratica, ao alterar ou suprimir, sem razão aparente ou por manipulação ostensiva." (BAHIA, 2009, p. 80). Todavia, os escritores não foram negligenciados e houve a chamada moeda de troca, pois, ao mesmo tempo em que ocorria a censura, o governo de Getúlio Vargas investia nos escritores para que eles recebessem cargos públicos ou auxílios diversos, caso se manifestassem a favor do regime (GARCIA, 2005).

Nesse sentido, destaca-se o escritor Jorge Amado, considerado o "bode expiatório" da censura de Vargas, que, em obras, retratava a realidade brasileira que o nacionalismo Varguista não queria expor e a realidade de crianças e adolescentes do estado da Bahia, que viviam nas ruas com suas vidas marginalizadas, praticando roubos e fazendo do cais do porto seu abrigo. Foi assim que surgiu Capitães da areia. "Porque fizeram do cais o seu quartelgeneral" (AMADO, 2007, p. 6), nome que fez jus à obra desse escritor baiano de 1937. Escrita em 1937, a obra Capitães da areia não foi bem vista pela 
ditadura nacionalista de Getúlio Vargas. Definitivamente, o objetivo da DD estava sendo contrariado na obra, devido aos diversos trechos que acusavam as mazelas sociais no período estadista de Vargas.

Alguns trechos dos livros de Jorge Amado foram alvo da censura em nome da moral e dos bons costumes. Do livro, Mar Morto, o romance que tem como núcleo a beira do cais da Bahia, conta a história dos personagens principais, Guma e Lívia. Na abertura dessa obra, Jorge Amado diz que é “[...] uma história da vida e do amor no mar." (AMADO, 2004, p. 1). Ao retratar o cotidiano dos navegantes do mar e da sociedade que girava em torno do cais, o autor mostra, por meio de terceiros personagens, as preocupações com os viajantes que iam a velejo no mar e a influência da beira do cais na vida dos moradores.

O romance traz, em alguns trechos, a descrição detalhada do amor sexual. Na beira do cais, Lívia é apresentada olhando o mar, ouvindo "os gemidos de amor de Maria Clara" (AMADO, 2004, p. 7). Esse foi um dos motivos pelos quais a obra entrava em conflito com os ideais do governo Vargas. Em diferentes trechos, o autor dá ênfase aos gemidos de Maria Clara e descreve com detalhes a conotação sexual, com o objetivo de induzir o leitor a imaginar a proposta da cena. A seguir, destaca-se o trecho em que Lívia está olhando para o mar e desconcentrada devido aos gemidos de Maria Clara:

Seu longo corpo moreno se voltou todo para os gemidos de Maria Clara. Estava negro no cais, uma ou outra lanterna brilhava nos saveiros, mas ela distinguia perfeitamente o de mestre Manuel de onde vinham os gemidos [...] ali um homem e uma mulher se amavam e os seus gemidos chegavam até Lívia (AMADO, 2004, p. 9).

Os peitos de Lívia aparecem sob o vestido. Todos no cais a desejavam. No livro, O País do Carnaval (1931), o primeiro romance escrito por Jorge Amado, em 1931, ele faz críticas à contradição relativa a essa festa nacional, o carnaval, por meio do personagem Paulo Rigger. Ele é um brasileiro que voltou de Paris, onde esteve durante sete anos, chegou ao Brasil e, junto com os 
intelectuais da Bahia, analisava o caminho da cultura, da economia e da política de sua pátria.

O romance é preenchido de acontecimentos que envolvem da sexualidade às revoluções que estavam se perpetuando na década de 1930 como, por exemplo, a Revolução de 30 do café com leite que ocorria no Brasil. Essas são formas explícitas de preferências políticas que se desenrolam nos diálogos. Pontes ressalta que Jorge Amado "[...] aborda as questões históricas da época: a insatisfação com a Revolução de 1930, a relação do jornalismo com a política, o debate em torno da identidade nacional e a ascensão do fascismo e do comunismo" (PONTES, 2009, p. 149). Esses assuntos iam de encontro ao que o governo proibia debater de forma crítica. Para entender os dissabores que a obra trazia para as autoridades ditatórias, analisam-se alguns trechos que contrariavam o que o governo Estado Novista não permitia nas expressões artísticas.

O romance começa com a cena em que Paulo Rigger estava em um navio voltando para o Brasil e conhece uma meretriz francesa, Julie, que também estava vindo para o Brasil, e a descreve:

\footnotetext{
Uma mulher que amava por dinheiro, sem amor. Que lhe poderia dar de novo? Prazer, ele conhecia muito. Carne... Mas o amor talvez não fosse somente carne... Talvez fosse alguma coisa mais... Essa outra coisa, ele não conhecia. Afirmava até que ela não existia. Existisse ou não, a francesinha não lhe poderia dar. Daria somente o sexo... E do mesmo modo de sempre. (AMADO, 2011, p. 6).
}

Esse foi o primeiro assunto que arriscava a obra como imprópria para a lei do Estado Novo. A relação sexual com uma meretriz não só desmoralizava a obra, como também demonstrava, indiretamente, que o país estava recebendo prostitutas. Para o governo ditatorial, isso significava perversão e rompimento da cultura dos bons costumes. Em um governo que prezava pelas formas tradicionais de convivência, abordar a erotização de uma meretriz ia contra a medida conservadora do governo do Estado Novista. Nesse outro trecho, o autor mostra a sensualidade da mulher, quando Rigger refere-se à Julie dizendo: "o seio molhado parecia querer pular fora da blusa”. 
Percebe-se que o romance $O$ País do Carnaval fazia parte de um dos critérios que classificaria livros como impróprios para circulação. Hallewell (2005, p. 456) refere que "o critério poderia, certamente, ser a linguagem franca, ou o erotismo no tema ou no tratamento, tanto quanto a inaceitabilidade política". Essas sequências estavam inseridas em todo o contexto do romance que ora criticava as relações sociais, ora explicitava a desilusão patriótica.

A questão política foi um ponto explícito que contradizia diretamente o governo, porque Rigger falava diretamente de sua preferência pelo comunismo e debatia, ironicamente, sobre a situação política do país. Em uma conversa com intelectuais, o personagem central da obra fala: "Mas é exatamente por isso que eu sou comunista[...] O comunismo mandaria surrar os brasileiros três vezes por dia. O povo endireitava [...] No Brasil, eu sou comunista prático. O único remédio eficaz para o brasileiro é o chicote." (AMADO, 2011, p. 48). Nesse trecho, observam-se a desilusão e a frustração que Rigger vivenciava no Brasil, em meio ao desemprego e à desordem, e sua crítica direta à inércia do povo brasileiro em relação aos problemas sociais do Brasil.

Assim como nas obras do escritor José Lins do Rego, que mostravam a realidade social e econômica da época de 30, no estado provisório, Menino de Engenho trazia o drama de um menino chamado Carlinhos que saiu do seio familiar, devido aos conflitos, e foi morar no engenho com seu avô, onde passou por diversas experiências, entre elas, a erótica.

Um dos exemplos que provocou a censura da obra é este trecho, em que o protagonista faz alusão ao erotismo e a uma doença venérea: “Apanhei doença do mundo. Escondi-me muitos dias do povo da casa-grande [...] E comecei a envaidecer-me com a minha doença. Abria as pernas, exagerando no andar. Era uma glória para mim essa carga de bacilos que o amor deixara pelo meu corpo imberbe" (REGO, 2001, p. 130).

As obras causaram escândalo para o DIP, que se sentiu desafiado com os escritos da obra de José Lins e de Jorge Amado, pois transgrediam o decreto de 1939 sobre publicações. No entanto, foi devido às obras deste último que os ânimos dos controladores do DIP tomaram grandes proporções, e o interventor 
da Bahia, Juracy Magalhães, mandou que tomasse medidas contra as obras dos escritores baianos.

\begin{abstract}
Uma grande fogueira de livros ardia, grossos rolos de fumaça escureciam o céu e um forte cheiro de papel queimado se espalhava pelas imediações da parte baixa do Elevador Lacerda. Não era um incêndio comum, mas a queima de 1.827 livros considerados 'propagandistas do credo vermelho', como eram chamados pelos militares que, nos dias anteriores, tinham percorrido as livrarias da cidade e apreendido quantos exemplares encontraram. Entre os livros que viraram cinzas naquela tórrida tarde primaveril mais de $90 \%$ - eram de autoria de um jovem jornalista e escritor baiano: Jorge Amado. (RAMOS, 2012, p. 30).
\end{abstract}

Embora as obras de Jorge Amado tenham sido as que predominaram na queima, Monteiro Lobato esteve entre os que passaram pelo processo de censura. Suas obras infantis faziam críticas ao governo getulista de forma sutil, como O poço do Visconde (1937), em que o autor dizia que, no Brasil, havia petróleo ${ }^{5}$, enquanto os peritos do governo de Vargas negavam a acusação. "O livro de Peter Pan e o livro História do mundo para crianças (1933) também foram retirados da biblioteca do Distrito Federal e queimados na fornalha de amortizações." (LUCA, 2004, p. 153).

A poetisa Cecília Meireles foi mais uma das intelectuais perseguidas no período, acusada de ser comunista. A tradução que fez do livro, As aventuras de Tom Sawyer (HALLEWELL,2005, p. 457), foi apreendida, assim como sua biblioteca que foi fechada.

Com o advento do Estado Novo em 1937, a polícia política da época fechara com truculência a pioneira biblioteca brasileira para crianças que ela e o primeiro marido fundaram, o artista plástico e ilustrador, Fernando Correia Dias, no Bairro de Botafogo, no Rio de Janeiro. (GOUVÊA, 2008, p. 194).

Ao mesmo tempo em que difundia a leitura, o INL trabalhava juntamente com o DIP, produzindo livros com a intenção de encobrir a informação para a sociedade. O DIP censurava obras, para que o INL tivesse campo aberto para disseminar seus livros. Nesse contexto, pode-se questionar o papel do INL 
acerca de sua atuação e se realmente pode ser visto de forma louvável, uma vez que os investimentos existiram, mas de forma solércia e cerceada. As bibliotecas estavam na dependência centralizadora do Estado que, por sua vez, conforme Oliveira (1994, p. 46), era "tutor e paternalista no quesito de definir o que deveria ser lido". Desse modo, a leitura objetivava mecanizar o entendimento no sentido de adestrar o que deveria ser lido.

\section{Considerações finais}

A pesquisa contribuiu para entendermos o percurso histórico dos livros e das bibliotecas no Estado Novo, no cenário político brasileiro, muito falado e debatido. No entanto, na abordagem crítica, percebeu-se que pouco se direciona à temática sobre as situações das bibliotecas e como, no Brasil, houve o acesso ao conhecimento e às políticas por meio dos livros.

Ao longo da pesquisa, foram estudadas as formas como as bibliotecas receberam a influência do Estado novista, em seus acervos, de forma centralizada, em detrimento dos interesses do governo em questão. Mesmo com a disseminação de livros, esses registros informacionais foram perseguidos e vistos como um inimigo político, e os livros também foram um dos meios mais utilizados para marcar a ideologia "do homem novo" na era Vargas.

Assim, considera-se que o livro e a leitura constituíram uma política de Vargas com o Estado Novo, sobretudo com a criação do INL, com o objetivo de livrar a sociedade dos "livros maus", um ato perigoso na propaganda, instanciado em nome da moral e dos bons costumes e, por conseguinte, alvo da censura e de repressão à liberdade de se expressar de grandes autores brasileiros citados neste estudo, como Jorge Amado, Monteiro Lobato, Cecília Meireles e José Lins do Rego.

A prática da propaganda e da censura revelou atos perigosos e é preciso estar atento ao fato de que a informação não passou por um processo de emancipação e de democratização, razão pela qual há uma tendência a não se perceberem práticas regimentares que ainda trazem vestígios conservadores, 
como a do Estado Novo, devido às tradições habituais instauradas nos ambientes em que se trabalha, onde há um clima de vigilância, nas instituições e nas bibliotecas devotas dessas práticas, aprisionadas no silêncio e atrofiadas na transferência do conhecimento.

\section{REFERÊNCIAS}

ACADEMIA Brasileira de letras. Biografia [de] Augusto Meyer. 2015.

AMADO, Jorge. Capitães da areia. Rio de Janeiro: Record, 2007.

AMADO, Jorge. O país do carnaval. Rio de Janeiro: Companhia das Letras, 2011.

AMADO, Jorge. Mar morto. Rio de Janeiro: Record, 2004.

BAHIA, Benedito Juarez. História, jornal e ética: as técnicas do Jornalismo. Rio de Janeiro: Mauad X, 2009.

BOMENY, Helena. Três decretos e um ministério: a propósito da educação brasileira no Estado Novo. In: PANDOLFI, Dulce (Org.). Repensando o Estado Novo. Rio de Janeiro: Editora FGV, 1999.

BRASIL. Decreto-Lei n. 5.077, de 29 de dezembro de 1939. Aprova o regimento do Departamento de Imprensa e Propaganda (D.I.P.). Diário Oficial [da] União, Rio de Janeiro, RJ, 29 dez. 1939. Seção 1, p. 29444.

BRASIL. Decreto-lei n. 93, de 21 de dezembro de 1937. Cria o Instituto Nacional do Livro. Diário Oficial [da] União, Rio de Janeiro, RJ, 27 dez. 1937. Seção 1, p. 25586.

BRASIL. Constituição (1937). Constituição dos Estados Unidos do Brasil de 10 de novembro de1937. Diário Oficial [da] União, Rio de Janeiro, 10 nov. 1937. Seção 7, p. 22365.

CAPANEMA, Gustavo. Exposição de motivos. Diário Oficial [da] União, Rio de Janeiro, RJ, 27 dez. 1937. Seção 1, p. 25586.

CAPELATO, Maria Helena Rolim. Propaganda política e controle dos meios de comunicação. In: PANDOLFI, Dulce (Org.). Repensando o Estado Novo. Rio de Janeiro: FGV, 1999.

CARVALHO, Marcus Vinicius Corrêa. O Instituto Nacional do Livro e os modernistas: questões para a história da educação brasileira. Cadernos de História da Educação, Uberlândia, v. 11, n. 2, 2012. 
D’ARAÚJO, Maria Celina Soares (Org.). Getúlio Vargas. Brasília: Câmara dos Deputados, Edições Câmara, 2011.

D’ARAÚJO, Maria Celina Soares. O Estado Novo. Rio de Janeiro: Jorge Zahar, 2000.

FEDERAÇÃO INTERNACIONAL de Associações e Instituições

Bibliotecárias; Organização das Nações Unidas para a Educação, a Ciência e a Cultura. Manifesto da IFLA/UNESCO sobre Bibliotecas Públicas. 1994.

FRANKE JÚNIOR, Claudir Lourival. Leitura para emancipação. Francisco Beltrão: Calgan Editora Gráfica, 2013.

FUNDAÇÃO GETÚLIO VARGAS. Centro de Pesquisa e Documentação de História Contemporânea do Brasil. Cartilha Getúlio Vargas para crianças 1942. Rio de Janeiro, 1942. Documento CPDOC/CDA Rev.30.

FUNDAÇÃO GETÚLIO VARGAS. Centro de Pesquisa e Documentação de História Contemporânea do Brasil. Livro juventude no Estado Novo. Rio de Janeiro, [19--]. Documento CPDOC/CDA GV-133f.

GARCIA, Nelson Jahr. Estado Novo, ideologia e propaganda política. São Paulo: Rocket Edition, 2005.

GETÚLIO Dornelles Vargas [verbete]. In: FUNDAÇÃO GETÚLIO VARGAS. Centro de Pesquisa e Documentação de História Contemporânea do Brasil.

Dicionário Histórico-Biográfico Brasileiro. São Paulo: FGV, 2010.

GIL, Antônio Carlos. Como elaborar projetos de pesquisa. 4. ed. São Paulo: Atlas, 2002.

GINZBURG, Carlo. Mitos, emblemas, sinais: morfologia e história. São Paulo: Companhia das Letras, 1989.

GOMES, Ângela Maria de Castro. A construção do homem novo: o trabalhador brasileiro. In: OLIVEIRA, Lúcia Lippi; VELLOSO, Mônica Pimenta; GOMES, Ângela Maria de Castro. Estado Novo: ideologia e poder. Rio de Janeiro: Zahar editores, 1982.

GOUVÊA, Leila Vilas Boas. Pensamento e "lirismo puro" na poesia de Cecília Meireles. São Paulo: EDUSP, 2008.

HALLEWELL, Laurence. O livro no Brasil: sua história. São Paulo: EDUSP, 2005.

HOBSBAWM, Eric. A história de baixo para cima. In: HOBSBAWM, Eric.

Sobre História. São Paulo: Companhia das Letras, 1998. 
HORTA, José Silvério Baia. Gustavo Capanema. Recife: Massangana, 2010.

JAMBEIRO, Othon et al. Tempos de Vargas: o rádio e o controle da informação. Salvador: EDUFBA, 2004.

LEILÕES BR. [Livro Uma biografia para gente nova]. Rio de Janeiro, c2017. Figura de livro à venda.

LEITÃO, Bárbara Júlia Menezello. A relação entre bibliotecas públicas, bibliotecários e censura na Era Vargas e no Regime Militar: uma reflexão. Niteró: Intertexto, 2011.

LOBATO, Monteiro. O poço do Visconde. São Paulo: Brasilense, 1965.

LUCA, Tânia Regina de. Monteiro Lobato: estratégias de poder e auto-repressão n'A barca de Gleyre. In: GOMES, Ângela Castro de (Org.). Escrita de si, escrita da história. Rio de Janeiro: FGV, 2004.

MORAES, Rubens Borba de. O problema das bibliotecas brasileiras. Rio de Janeiro: Casa do Estudante do Brasil, 1943.

NOVAES, José. Um episódio de produção de subjetividade no Brasil de 1930: malandragem e Estado Novo. Psicologia em Estudo, Maringá, v.6, n.1, jan./jun. 2011.

OLIVEIRA, Zita Catarina Prates de. A biblioteca "fora do tempo": políticas governamentais de bibliotecas públicas no Brasil: 1937-1989. 1994. Tese (Doutorado em Ciência da Comunicação) - Escola de Comunicações e Artes, Universidade de São Paulo, São Paulo. 1994.

PANDOLFI, Dulce. Repensando o Estado Novo. Rio de Janeiro: Fundação Getúlio, 1999.

PONTES, Matheus de Mesquita. Jorge Amado e a Literatura de combate: da literatura de engajada à literatura militante de partido. REVELLI-Revista de Educação, Linguagem e Literatura, v. 1, n. 2, p. 147-161, 2009.

RAMOS, Jorge. Ditadura Vargas incinerou em praça pública 1.640 livros de Jorge Amado. Correio, Salvador, 10 ago. 2012.

REGO, Jose Lins. Menino de Engenho. Rio de Janeiro: José Olympio, 2001.

SCHWARTZMAN, Simon. Estado novo: um auto-retrato. Brasília: UNB, 1982.

SEBO DO MESSIAS. [Livro Biografia do Marechal Floriano Peixoto]. São Paulo, [20--]. Figura de livro à venda. 
SILVA, Luiz Eduardo Ferreira da. Ciência como técnica ou técnica como ciência: nas trilhas da Arquivologia e seu status de cientificidade. 2013.

Dissertação (Mestrado em Ciência da Informação) - Universidade Federal da Paraíba, João Pessoa, 2013.

SOARES, Gabriela Pellegrino. Semear horizontes: uma história da formação de leitores na Argentina e no Brasil, 1915-1954. Belo Horizonte: UFMG, 2007.

TACHIZAWA, Takeshy; MENDES, Gidazio. Como fazer monografia na prática. 12. ed. Rio de Janeiro: Editora FGV, 2006.

VERGUEIRO, Waldomiro de Castro Santos. Censura e seleção de materiais em bibliotecas: o despreparo dos bibliotecários brasileiros. Ciência da Informação, Brasília, v. 16, n. 1, 1987.

VIANNA, Marly de Almeida Gomes; SILVA, Érica Sarmiento da; GONÇALVES, Leandro Pereira (Org.). Presos políticos e perseguidos na Era Vargas. Rio de Janeiro: Faperj, 2014.

\title{
(Re) visiting the Estado Novo in Brazil: an analysis of censorship and cultural dissemination of books in libraries
}

\begin{abstract}
The article about the relations between censorship and the measures of implementation of the cultural dissemination of the books in the libraries, in the Estado Novo, in Brazil. It presents a theoretical approach of a historical, bibliographic and documentary nature, in which the indicium knowledge was adopted by which interpretative aspects of other forms of knowledge that share the clues and footprints through indirect knowledge are evidenced. Considerations are made on the development of the Instituto Nacional do Livro in libraries, under the influence of the Estado Novo, and the relation of censorship with the Departamento de Imprensa e Propaganda, which was connected to the interests of the government in relation to the expansion and dissemination of books. It is considered that the book and the reading were great efforts in the politics of Vargas in the Estado Novo, with the creation of Instituto Nacional do Livro, a dangerous act, in advertising, instanced in the name of morality and good manners and, as a result of censorship and repression of the freedom of expression of the great Brazilian authors, such as Jorge Amado, Monteiro Lobato, Cecilia Meireles and José Lins do Rego. Therefore, it is necessary to question, because there is still a tendency to the conservative vestiges, such as the ones from Estado Novo due to the usual traditions established in the work environments, the climate of vigilance in the institutions and the common policies in libraries.
\end{abstract}


Keywords: Estado Novo - Brazil. Instituto Nacional do Livro. Censorship. Books. Libraries.

Recebido: 30/01/2018

Aceito: $17 / 04 / 2018$

${ }^{1} \mathrm{O}$ caçador teria sido o primeiro a 'narrar uma história', porque era o único capaz de ler, nas pistas mudas, uma série coerente de eventos. 'Decifrar' ou 'ler' as pistas dos animais são metáforas (GINZBURG, 1989, p. 152).

${ }^{2}$ Anteriormente chamado de Instituto Cairu, foi desativado em 1936. Seu único objetivo era de fazer uma enciclopédia brasileira e o dicionário da língua nacional. "O instituto foi criado pelo decreto $\mathrm{n}^{\circ}$ 93, de dezembro de 1937, que determinava que o Instituto Cairu fosse transformado em Instituto Nacional do Livro." (CARVALHO, 2012, p. 545). Da forma que o INL ainda visava concluir os objetivos do extinto Instituto Cairu, da criação das enciclopédias e do dicionário, mas também advinha com novos objetivos expansionistas em seus decretos - o que será visto na próxima página.

${ }^{3}$ Nascido em Minas Gerais, foi nomeado por Vargas, em 26 de julho de 1934, para administrar a educação e a saúde pública até 1945 — ano da queda de Getúlio Vargas (HORTA, 2010, p. 19).

${ }^{4}$ Nascido em Porto Alegre, foi jornalista, poeta e diretor da Biblioteca Pública do estado de Porto Alegre, de 1930 a 1936. Foi transferido para o Rio de Janeiro por Getúlio Vagas, em 1937, para dirigir o Instituto Nacional do Livro, de onde foi diretor durante 30 anos (ACADEMIA..., 2015, doc. não paginado).

5 Conforme Lobato (1965), "Petróleo o Brasil tem para abastecer o mundo inteiro durante séculos. Há sinais de petróleo por toda parte [...] A superfície de todos os Estados está cheia dos mesmos indícios de petróleo.” (LOBATO, 1965, p. 57). 